\title{
Reflection of Epidemiological Impact on Burden of Injury in Tertiary Care Centre, Pre-COVID and COVID Era: "Lockdown, a Good Fortune for Saving Life and Limb"
}

\author{
Amita Jain $^{1} \cdot$ Vishal Goyal $^{1}$ (D) $\cdot$ Chaitanya Varma $^{1}$ \\ Received: 22 July 2020 / Accepted: 14 October 2020 / Published online: 24 October 2020 \\ (C) Association of Surgeons of India 2020
}

\begin{abstract}
Road traffic injuries continue to be a major public health concern and are a leading cause of death and injury across the world. Road transport remains the most favoured mode of transport for both freight and passenger movement in India. As per the World Health Organization, approximately 1.35 million people die annually on the world's roads, and another 20 to 50 million sustain nonfatal injuries as a result of road traffic crashes. These injuries and deaths have an immeasurable impact on the families affected, whose lives are often changed irrevocably by these tragedies, and on the communities in which these people lived and worked. India ranks 1 in the total number of traffic-related deaths across the 199 countries reported in the World Road Statistics, 2018, followed by China and the USA due to its large population (India, 21.7, and China, 18.6, fatalities per 100,000), although several Central American and African countries have higher fatality rates. During COVID-19 (coronavirus disease-19) pandemic, a national lockdown was implemented by Government of India from 24 March to 31 May 2020, in four phases to control the spread of SARS CoV-2 (severe acute respiratory syndrome coronavirus-2) infection. In our observational study, we compared the epidemiology of trauma patients of two periods from 1 April to 31 May 2019 and 24 March to 31 May 2020 and found out that unique concept of lockdown with stringent implementation of discipline, alcohol ban, behavioural change in visiting family and friends as minimum as possible, promoting work from home and digital classes for school and colleges lead to phenomenal decrease in traffic-related injuries and fatality. The lockdown has grossly decreased 'disability-adjusted life year'(DALY), an outcome indicator for cost-effective analysis, which is calculated as the value of future years of healthy life lost to morbidity/ disability and future years of life lost to premature mortality.
\end{abstract}

Keywords Trauma $\cdot$ Injury $\cdot$ Road traffic injuries $\cdot$ Epidemiology $\cdot$ COVID pandemic

\section{Introduction}

The World Health Organization (WHO) defined injury as the damage caused by acute exposure to physical agents such as mechanical energy, heat electricity, chemicals and ionising radiation interacting with the body in amounts or at rates that

Amita Jain

jainamitadr@yahoo.in

Vishal Goyal

drgoyalvishal@gmail.com

Chaitanya Varma

ksvshchaitanyavarma@gmail.com

1 Army College of Medical Sciences \& Base Hospital Delhi Cantt, New Delhi, India exceed the threshold of human tolerance [1]. Injury is a major contributor of ill health and disability. As per WHO, approximately 1.35 million people die annually on the world's roads, and another 20 to 50 million sustain nonfatal injuries as a result of road traffic crashes. These injuries and deaths have an immeasurable impact on the families affected, whose lives are often changed irrevocably by these tragedies, and on the communities in which these people lived and worked. Road traffic injuries are estimated to be the eighth leading cause of death globally. They are the leading cause of death for young people aged 15-29 years, and as a result take a heavy toll on those entering their most productive years [2].

Injuries have been classified into two broad categories: unintentional injuries and intentional injuries. Unintentional injuries include road traffic injuries, falls, burns, poisoning and drowning. Intentional injuries include interpersonal 
violence/homicide, self-inflicted injuries/suicides and war. Injuries are also classified based upon the place of injury, domestic injuries, injuries at public places, and the settings of injuries like recreational injuries and occupational injuries [3]. The 'disability-adjusted life year' (DALY) is a time-based measure that combines years of life lost owing to premature death and years of life lost due to time lived in states of less than full health [4]. In 2004, the WHO ranked road traffic injuries as the ninth leading cause of DALYs. By 2030, such injuries are projected by the WHO to rank third [2, 5]. DALY is an outcome indicator for cost-effective analysis, and the calculation of DALY is beyond the scope of this study.

The overall global road traffic fatality rate is 18.2 per 100,000 population. However, middle-income countries have the highest annual road traffic fatality rates, at 27.5 per 100,000 , while the rate in high-income countries is lowest, at 8.7 per $100,000[6]$.

According to a report of the Ministry of Home Affairs, Government of India, one accident occurs every $2 \mathrm{~min}$ and one suicide every $5 \mathrm{~min}$ in India, with the accident rate corresponding to 45 per 100,000 population. The number of 'traffic injuries' in India were 474,638 in 2018 , a total of 71,258 traffic injuries were reported in 53 cities during 2018, and 71,258 traffic crashes caused injuries to 61,187 persons and 16,909 deaths. The maximum fatalities in traffic injuries were reported in Delhi City (2325 deaths) followed by Chennai (1260 deaths) [7]. India ranks 1 in the total number of traffic-related deaths across the 199 countries reported in the World Road Statistics, 2018, followed by China and the USA, due maybe to its large population (India, 21.7, and China, 18.6, fatalities per 100,000), although several Central American and African countries have higher fatality rates. As per the WHO Global Report on Road Safety 2018,
India accounts for approximately $11 \%$ of the road traffic-related deaths in the world [6].

The Government of India confirmed India's first case of SARS Cov-2 (severe acute respiratory syndrome coronavirus2) infection on 30 January 2020 in the state of Kerala, when a university student from Wuhan travelled back to the state. As the number of confirmed COVID-19 (coronavirus disease19)-positive cases crossed 500, on 24 March 2020, the Government of India announced 21-day national lockdown from 24 March to 14 April 2020, which was further extended until 3 May 2020. A third lockdown extending until 17 May was announced on 1 May 2020. This was followed by a partial and fourth lockdown till 31 May $2020[8,9]$.

Aim of Study The aim of this observational study is to analyse the various epidemiology factors associated with trauma in pre-COVID and COVID era during lockdown in a tertiary care hospital with level 1 trauma centre and a multidisciplinary 600-bed public hospital in Delhi NCR (National Capital Region).

\section{Objectives}

The objective of the study was as follows:

- Evaluate the epidemiology and pattern of injury in preCOVID and COVID era during national lockdown in patients visiting level 1 trauma centre in Delhi NCR.

Exclusion criteria:

- Patients declared dead on arrival (postmortem report was not available).
Fig. 1 Age-wise distribution of patients: 1 April to 31 May 2019

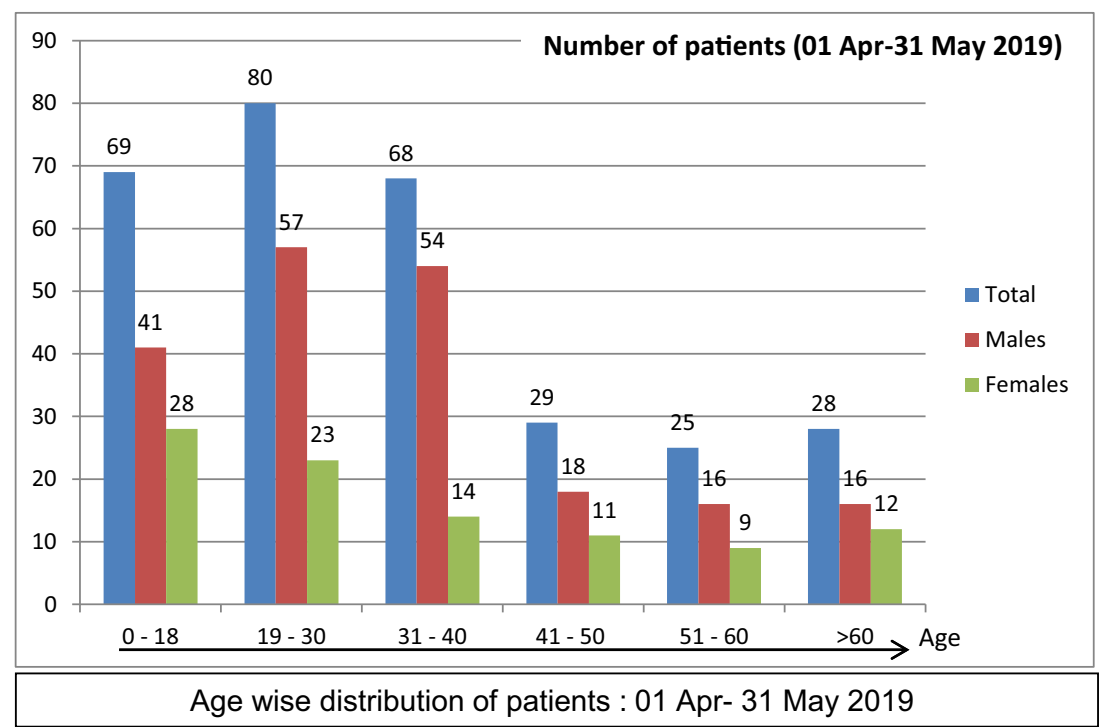


Fig. 2 Age-wise distribution of patients: 24 March to 31

May 2020

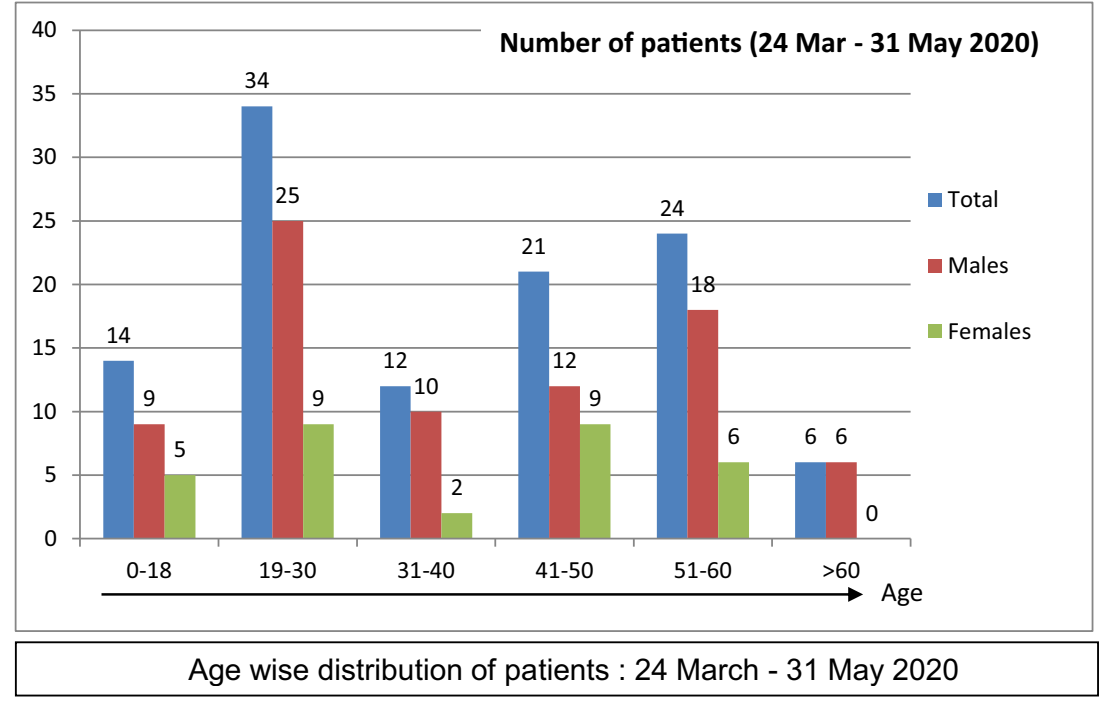

\section{Materials and Methods}

This was an observational study conducted at the level 1 trauma centre attached to a tertiary care hospital in Delhi NCR. Over a 2-month period (1 April 2019 to 31 May 2019), a total of 299 trauma victims presented to trauma centre. During national lockdown from 24 March to 31 May 2020, 111 trauma victims presented to trauma centre. A comprehensive history and examination of all patients was done and treated as per ATLS (Advanced Trauma Life Support) protocol. Details were noted with regard to age, sex, injury type (blunt/penetrating) and mode. The injuries were divided into subgroups based on anatomical region affected like head injury, thoracic injury, abdominal, pelvis fracture, and lower and upper limb injury, and minor injuries like lacerations, abrasions, sprains and strains.

\section{Results}

A total of 299 trauma victims presented to our trauma centre during study period (1 April 2019 to 31 May 2019, 61 days), making an average of approximately 4.9 victims per day. Out of which, the majority of patients were male $202(67.5 \%)$ as compared to $97(32.5 \%)$ victims were females. The average age of the victims was 29-30 years. The highest number of victims $(80,26.7 \%)$ were between 18 and 30 years of age followed by $31-40$ years $(68,22.74 \%)$ age group. About $72.5 \%$ of the victims (217) were under 40 years of age. There were 69 children (23\%) below 18 years of age with an average age of 1314 years. Out of total patients included in study, $172(57.5 \%)$ were married and 127 (42.5\%) were unmarried.

Among the injured patients, two-wheeler vehicle collision $(113,37.7 \%)$ constituted the maximum percentage, followed by fall $(483,28.75 \%)$. Blunt injuries $(292,97.65 \%)$ were more
Fig. 3 Mode of injury: 1 April to 31 May 2019

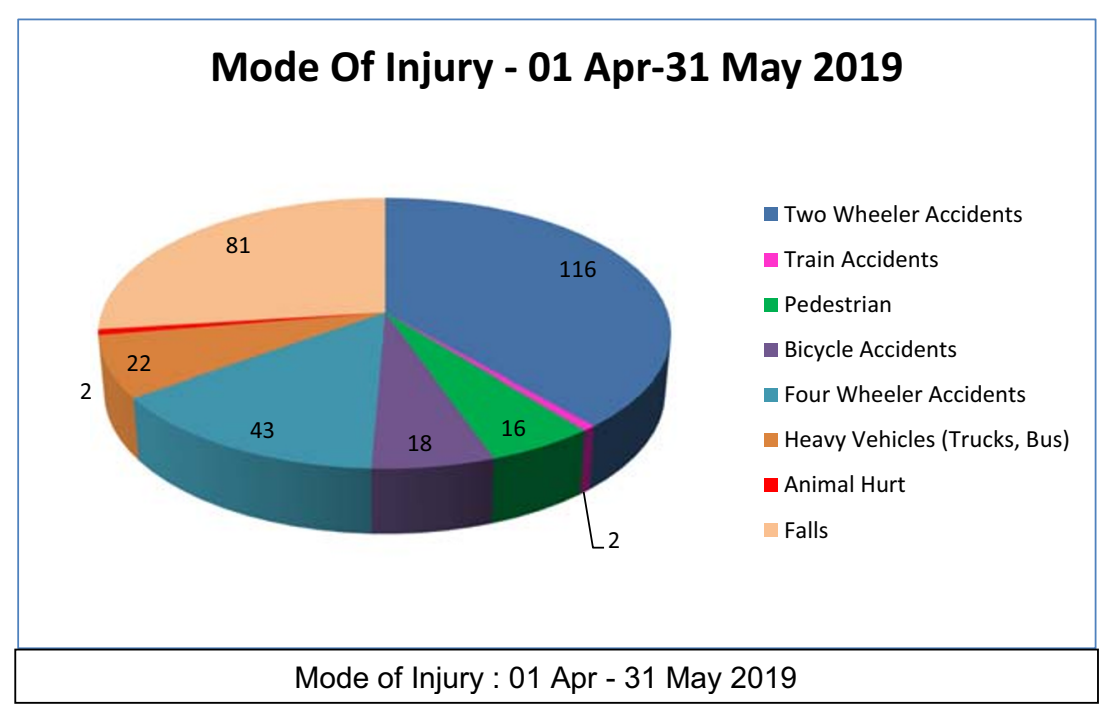


Fig. 4 Mode of injury: 24 March to 31 May 2020

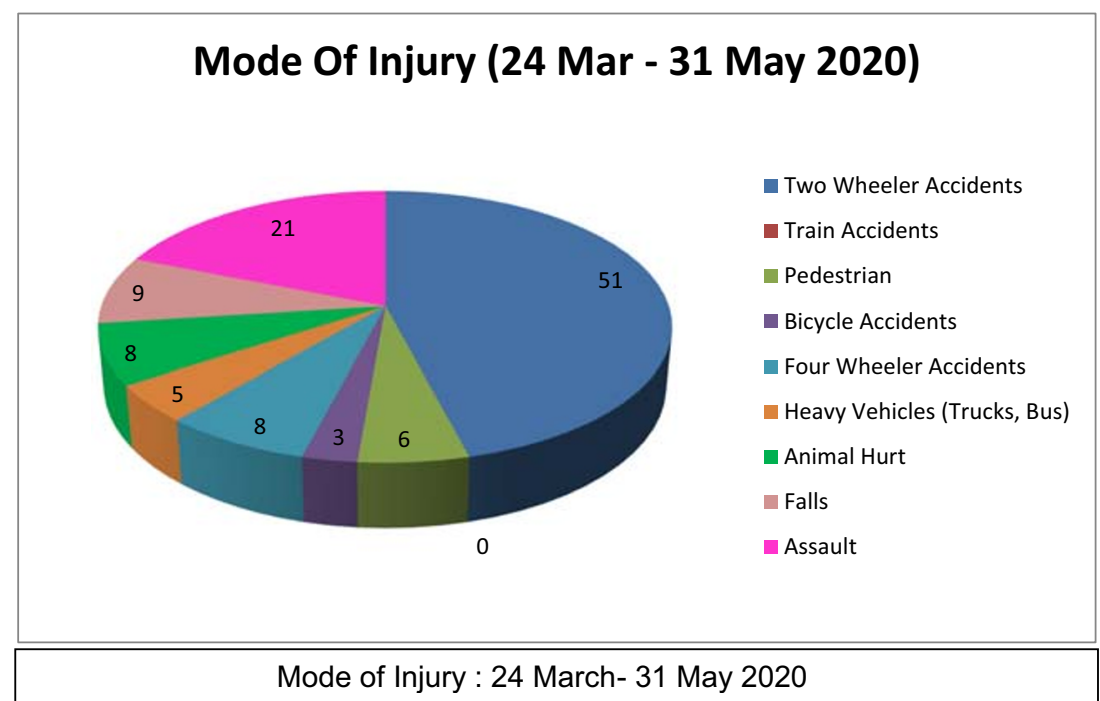

common than penetrating injuries. A total of $190(63.5 \%)$ victims suffered minor injuries, and head injury was the leading pattern of injury $(63,21.07 \%)$, followed by upper limb fractures $(47,15.7 \%)$ and abdominal injuries $(44,14.7 \%)$. Out of total patients (299), maximum number of patients (96, $32 \%$ ) were educated up to high school, followed by illiterate patients $(50,16.7 \%)$.

A total of 111 trauma victims presented to trauma centre of our hospital during national lockdown (24 March to 31 May 2020, 69 days), making an average of approximately 1.6 victims per day. Out of which, male $(80,72 \%)$ were majority as compared to $31(28 \%)$ female patients. The average age of the victims was 24 years. The highest number of victims $(34,29.8 \%)$ were between 19 and 30 years of age followed by $51-60$ years $(24,21.62 \%)$ age group. About $54 \%$ of the victims were under 40 years of age. There were only 14 victims $(4.6 \%)$ below 18 years of age. Out of total 111 patients, $64(57.65 \%)$ were married and $47(42.34 \%)$ were unmarried.
Among the injured patients, two-wheeler vehicle collision $(51,45.94 \%)$ constituted the leading mode of injury, followed by assault $(21,18.9 \%)$. Most of the victims suffered minor injuries $(52,46.8 \%)$, and upper limb fracture $(47,42.3 \%)$ was the leading pattern of injury followed by lower limb fracture $(28,25.2 \%)$ and head injury $(24,21.6 \%)$. Out of total (111) patients, maximum number of patients $(42,37.8 \%)$ were educated up to high school, followed by 27 (24.3\%) patients educated up to primary school (Figs. 1, 2, 3, 4, and 5).

\section{Discussion}

Road traffic injuries continue to be a major public health concern and are a leading cause of death and injury across the world. Road transport remains the most favoured mode of transport for both freight and passenger movement in India. The fast-growing population, exceptional rate of motorization

Fig. 5 Pattern of injury of patients

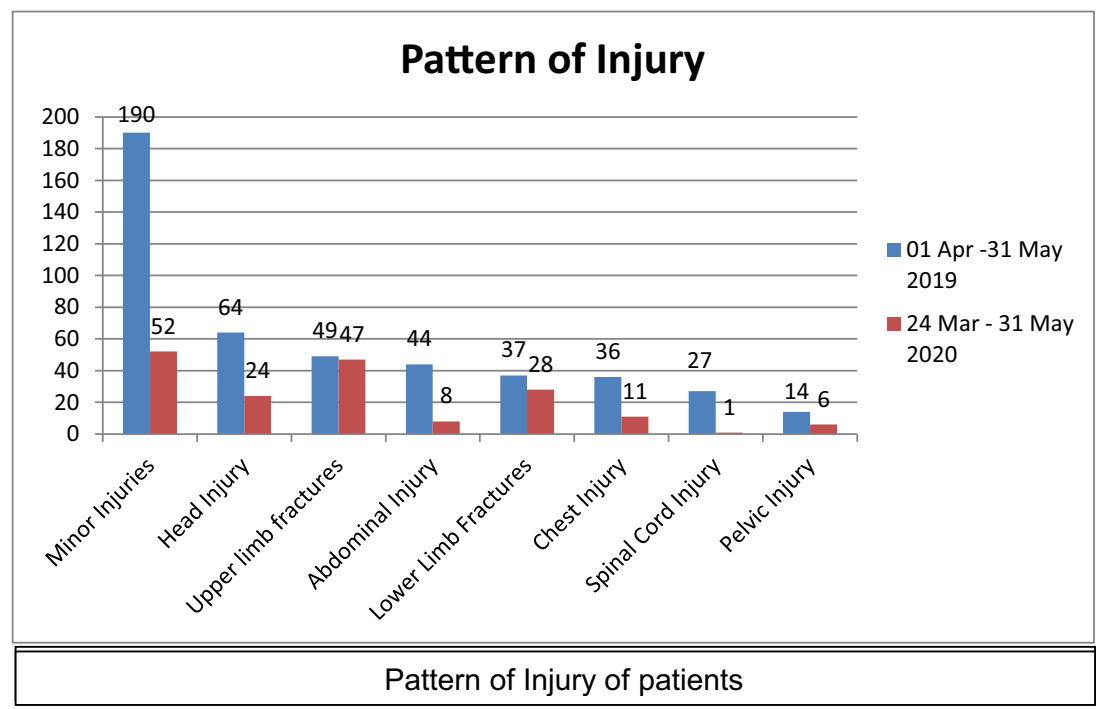


coupled with the ever growing urbanization has made people vulnerable to frequent road traffic injuries resulting in fatalities and injuries/disabilities. India is a signatory to the second global high level Conference on Road Safety held in Brazil in 2015, referred to popularly as the Brasilia Declaration, which inter alia, resolved to half the deaths and traffic-related injuries by 2020 and to include this target in the 2030 agenda for sustainable development by the participating countries [10].

In present study, during 1 April to 31 May 2019, the highest number of patients were in the 19-30 years of age $(80,26.7 \%)$, followed by $31-40$ years $(68,22.74 \%)$ age group. About $72.5 \%$ of the victims (217) were under 40 years of age. This age group is the most active phase of life, crazy for speed, during which there is tendency to take a risk. The lower proportion of victims above 60 years and in children could be due to general less mobility of this group. Similar observations were made in studies of Ramakant V. et al. [11] and Aggarwal K.K et al. [12]. In mode of injury, two-wheelers accounted for the highest share (37.7\%) in total injuries, which is comparable with study of Rastogi et al., in which share of two-wheelers was $32.1 \%$ [13]. Minor injuries accounted for the largest share of about $63.9 \%$.

When compared to number of patients injured during 1 April to 31 May 2019 (4.9 patients/day) with those injured during national lockdown from 24 March to 31 May 2020 (1.6 patients/day), a drastic decrease was noted. Increase in number of injured patients was noticed in the $3 \mathrm{rd}$ and 4 th phase of lockdown, during which liquor shops were allowed to open in Delhi. While close to 100 liquor vends were allowed to open in the 3rd phase of lockdown, about 200 shops were functional across the city in the 4th phase of lockdown [14].This increase may be attributed to the increase in road traffic and people driving under influence of alcohol; however, we have not assessed the alcohol status of the victims as it was not in scope of this study. Pattern of injury and affected age group remained the same as compared to pre-COVID levels (1 April to 31 May 2019).

Lockdown imposed restriction on 1.3 billion population across the country in day to day movement and ban on commercial and industrial activity. This has helped in achieving Brasilia declaration decreasing death rate to half in 2020.

\section{Conclusion}

Traffic discipline and lifestyle modification should be inculcated in this digital era, and promotion of only essential movement should be encouraged.

The epidemiology and pattern of injury in pre-COVID and COVID era has been evaluated, and it can be concluded that unique concept of lockdown with stringent implementation of discipline, alcohol ban, behavioural change in visiting family and friends as minimum as possible, promoting work from home and digital classes for school and colleges lead to phenomenal decrease in trauma morbidity and mortality.

\section{Compliance with Ethical Standards}

Conflict of Interest The authors declare that they have no conflict of interest.

\section{References}

1. Langley J, Brenner R (2004) What is an injury. Injury Prevention 10:69-71

2. WHO Project: ICP DPR 001, Strategic Plan for Injury Prevention and Control in South-East Asia, 2002. https://apps.searo.who.int/ PDS_DOCS/B1470.pdf (Accessed 13 June 2020)

3. Alhajyaseen W, Tiwari G (2019) Traffic safety research in the 15 th world conference on transport research. Int J Inj Control Saf Promot 26(3):203-204

4. Murray CJL, Acharya AK (1997) Understanding DALYs (disability-adjusted life years). J Health Econ 16:703-730

5. WHO Global status report on road safety 2013: supporting a decade of action. https://www.who.int/gho/publications/world health statistics/2020/en/ (Accessed 13 June 2020)

6. Global status report on road safety 2018: summary. Geneva: World Health Organization; 2018. https://apps.who.int/iris/handle/10665/ 277370 (Accessed 13 June 2020)

7. The Government of India, Ministry of Home Affairs, National Crime Record Bureau, Accidental deaths and suicides in India 2018. https://ncrb.gov.in/accidental-deaths-suicides-india-adsi (Accessed 13 June 2020)

8. Government of India. 2020. India fights corona COVID -19 . https://www.mygov.in/covid-19 (Accessed 15 July 2020)

9. Government of India, Ministry of home Affairs, Circulars for COVID-19. $2020 \mathrm{https}: / / w w w . m h a . g o v . i n /$ notifications/circularscovid-19 (Accessed 15 July 2020)

10. 2nd Global High Level Conference on Road Safety : The Brasilia Declaration on road safety. 2015. WHO/Violence and Injury Prevention. www.who.int/violence_injury_prevention/road traffic/Brasilia_Declaration/en/ (Accessed 15 July 2020)

11. Ramakant $V$ et al (2014) Profile of Death due to road traffic injuries brought to Dr.S. H. Medical College and Hospital Jodhpur. J Indian Acad Forensic Med 36(3)

12. Aggarwal KK, Oberoi SS (2009) Distribution of fatal road traffic accident cases. J Punjab Acad Forensic Medicine and Toxicology 9(1):9-11

13. Rastogi D, Meena S et al (2014) Epidemiology of patients admitted to a major trauma Centre in northern India. Chin J Traumatol 17(2): 103-107

14. Staff writer. Here's how much Delhi govt has earned through 'special corona fee' in 15 days. LiveMint (Delhi) [newspaper on internet]. 2020 May 24 [cited 15 July 2020]. Available from: https:// www.livemint.com/news/india/delhi-govt-liquor-sale-earningthrough-special-corona-fee-in-15-days-11590300260209.html

Publisher's Note Springer Nature remains neutral with regard to jurisdictional claims in published maps and institutional affiliations. 